\title{
A Silicon Ingot Lifetime Tester for Industrial Use
}

T.H. Wang, T.F. Ciszek, and M. Landry

National Renewable Energy Laboratory

\section{A. Matthäus}

Siemens Solar Industries; Camarillo, California

G. Mihalik

Siemens Solar Industries; Vancouver, Washington

Presented at the National Center for

Photovoltaics Program Review Meeting

Denver, Colorado

September 8-11, 1998

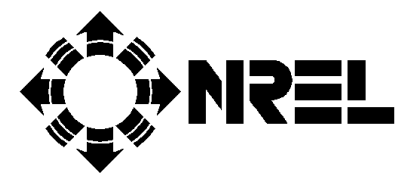

National Renewable Energy Laboratory 1617 Cole Boulevard

Golden, Colorado 80401-3393

A national laboratory of the U.S. Department of Energy Managed by Midwest Research Institute for the U.S. Department of Energy under contract No. DE-AC36-83CH10093

Work performed under task number PV902401

October 1998 


\begin{abstract}
NOTICE
This report was prepared as an account of work sponsored by an agency of the United States government. Neither the United States government nor any agency thereof, nor any of their employees, makes any warranty, express or implied, or assumes any legal liability or responsibility for the accuracy, completeness, or usefulness of any information, apparatus, product, or process disclosed, or represents that its use would not infringe privately owned rights. Reference herein to any specific commercial product, process, or service by trade name, trademark, manufacturer, or otherwise does not necessarily constitute or imply its endorsement, recommendation, or favoring by the United States government or any agency thereof. The views and opinions of authors expressed herein do not necessarily state or reflect those of the United States government or any agency thereof.
\end{abstract}

Available to DOE and DOE contractors from:

Office of Scientific and Technical Information (OSTI)

P.O. Box 62

Oak Ridge, TN 37831

Prices available by calling 423-576-8401

Available to the public from:

National Technical Information Service (NTIS)

U.S. Department of Commerce

5285 Port Royal Road

Springfield, VA 22161

703-605-6000 or 800-553-6847

or

DOE Information Bridge

http://www.doe.gov/bridge/home.html 


\title{
A Silicon Ingot Lifetime Tester for Industrial Use
}

\author{
T.H. Wang, T.F. Ciszek, M. Landry, A. Matthäus ${ }^{*}$, and G. Mihalik ${ }^{* *}$ \\ National Renewable Energy Laboratory, Golden, Colorado 80401 \\ *Siemens Solar Industries, Camarillo, California 93011 \\ ** Siemens Solar Industries, Vancouver, Washington 98682
}

\begin{abstract}
A specially designed lifetime measurement instrument has been developed to characterize silicon ingots before they are subjected to expensive slicing and solar-cell processing, thereby saving needless processing costs of inferior materials in a solar-cell production line. The instrument uses the direct-current photoconductance decay (DC-PCD) method for linear detection of the transient photoconductance signal and localized probing / illumination for necessary sensitivity on low resistivity and large samples. The instrument also has a compact and highpower laser diode as the light source, data averaging capability, a pneumatic ingot transport and probe positioning mechanism, and a user-friendly graphical interface for data acquisition / lifetime calculation / data storage / hardcopy for factory-floor use with quick turnaround. A 3-dimensional finite-element analysis indicates that the as-cut surface finish is adequate for measuring the bulk lifetime on the order of $50 \mu$ s or less. Measurement repeatability and clear distinction among different grades of feedstock materials have been demonstrated.
\end{abstract}

\section{INTRODUCTION}

In commercial production of crystalline-silicon solar cells, a variety of feedstock materials may be used due to cost and availability considerations. As a result, the Czochralski-silicon (CZ-Si) crystals could have varying impurity levels and defects that may render the crystals too inferior to yield decent cell efficiency. Lifetime characterization of the crystal ingots before slicing could save the unnecessary processing costs of these materials.

The direct-current photoconductance decay (DC-PCD) method is the standard technique that can give accurate lifetime values if certain conditions are met per ASTM standard [1], but it requires destructive and laborious sample preparation with electrical contacts and it is not applicable on large ingots directly. However, the commonly used contactless techniques, e.g., microwave reflection or radio-frequency photoconductance decay ( $\mu$-wave-PCD or RF-PCD), have a carrier-density-dependent skin effect that emphasizes surface recombination and non-linear circuit response to photoconductance and generally require a tuning operation for each measurement. Hence, a non-destructive, inexpensive, preparation-free, and easy-to-use instrument needs to be developed to measure bulk minority-carrier lifetimes on an as-cropped surface of a low-resistivity and large ingot. 


\section{LIFETIME TESTER}

We chose the DC-PCD method for circuit linearity and simplicity for the ingot lifetime tester. To eliminate the need for contact preparations and to generate a sufficient photoconductance decay signal for low-resistivity and large ingots, a pair of probes with ohmic-contact behavior with silicon is used. A long-pulsed laser beam ( 250- $\mu$ s width, $<100$-ns cut-off) is delivered onto the as-cropped silicon surface between the probes by a high-power (60-Wp) 940-nm laser diode array. A block diagram in Fig. 1 illustrates the system configuration.

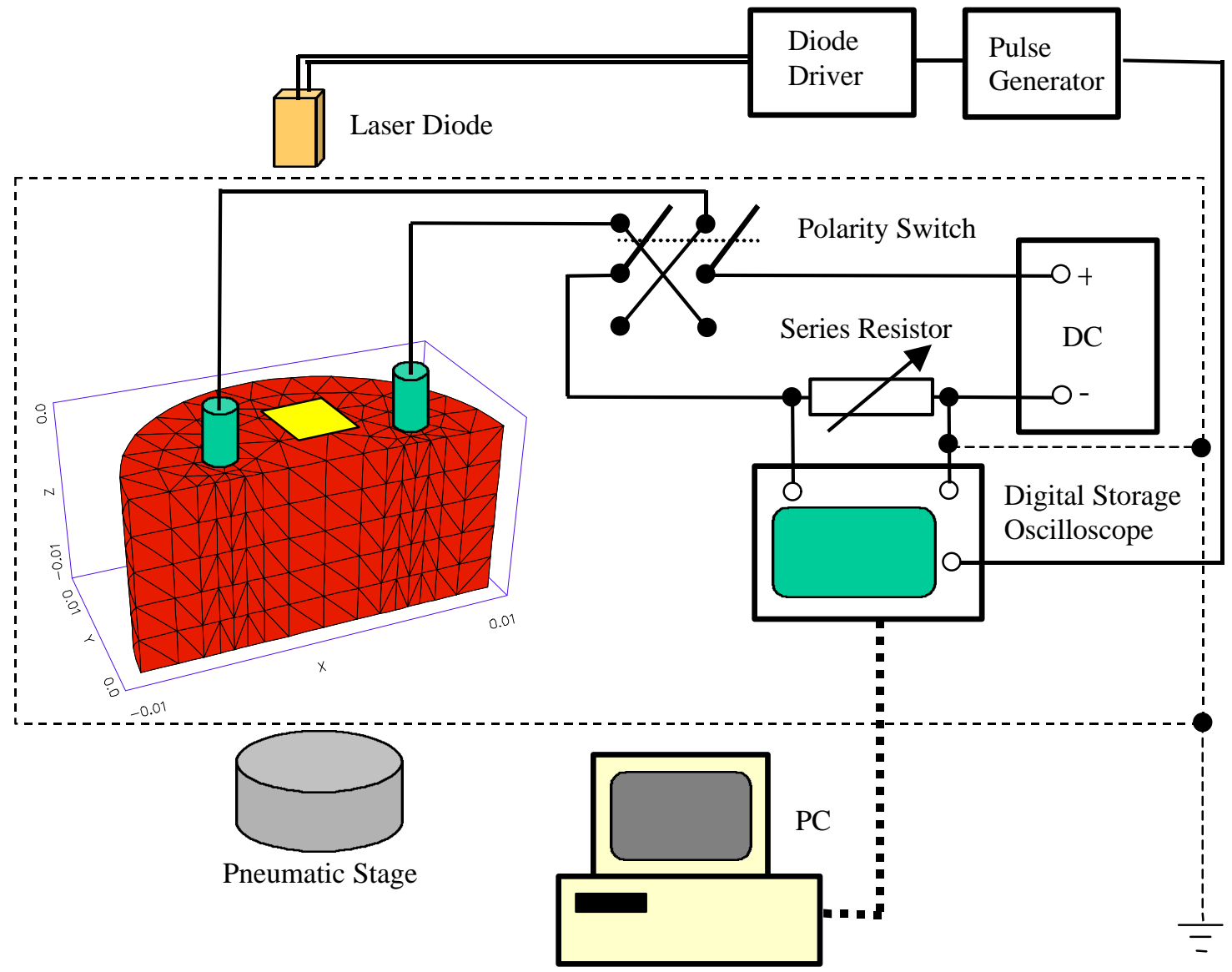

Fig. 1 Block diagram of the Lifetime Tester. Half of the silicon ingot sample is shown with the finite-element grid used for PCD simulation.

The photo-induced conductance transient is measured by the oscilloscope that averages, stores, and transmits the data to the PC running a graphical data acquisition program in LabVIEW ${ }^{\circledR}$. A least-squares fit to the data curve and an effective lifetime are calculated within a chosen time period. The program can then store the data for retrieval to refit at a different time interval and print out a hardcopy. The choice of the time interval for lifetime calculation and the relevance of the effective lifetime to the bulk 
lifetime will be discussed in the following section. The system has a pneumatic stage for positioning and bringing the ingot into contact with the probes. The load spring in the probe assembly, a proximity switch, and a limit switch determine the probe pressure, which does not affect a given measurement if the pressure is maintained during the signal transient. Fig. 2 is a picture of the instrument.

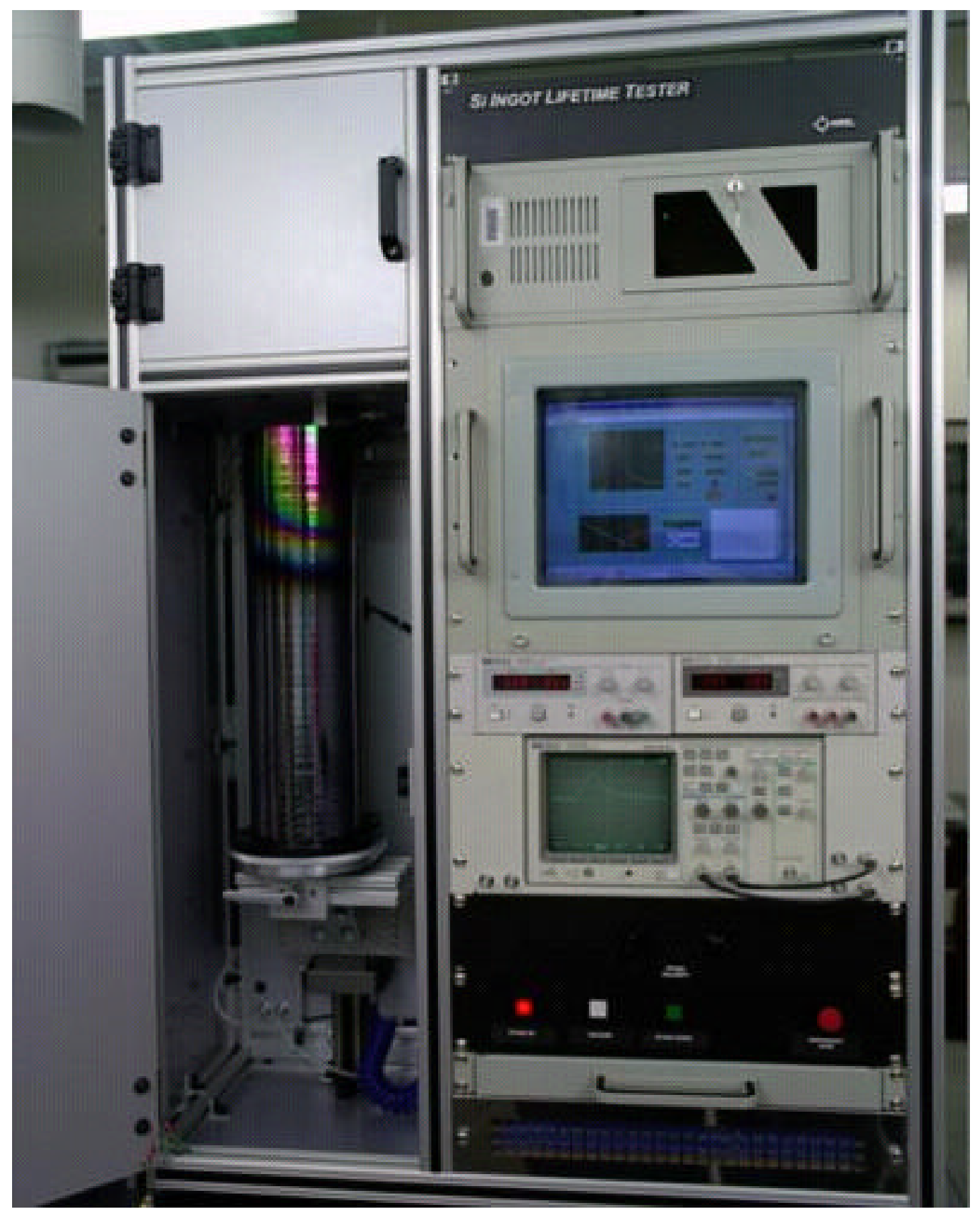

Fig. 2 The Silicon Ingot Lifetime Tester. 


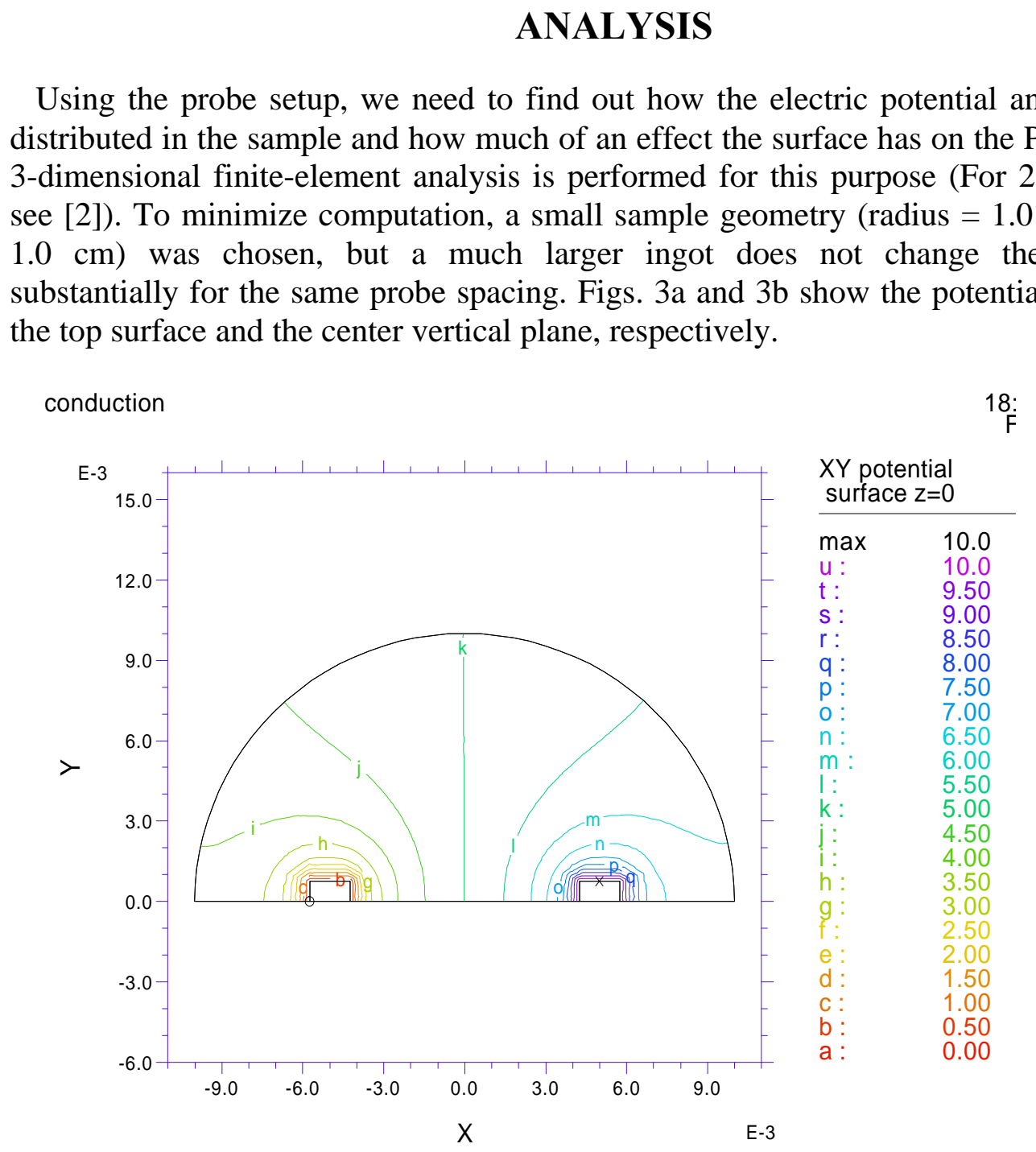

Fig. 3a Electric-potential contours on the top surface.

It is noted that even when a total voltage of 10 volts was applied between the two probes, only about 1 volt is actually dropped in the center excitation region of about 3mm width. A large voltage drop occurs around each probe tip, which makes the PCD signal sensitive to mechanic-stability of the contacts.

The current density in the center cross-section between the two probes, shown in Fig. 4, points out that the current is somewhat concentrated near the centerline (represented by the upper left corner) between the probes, and yet, it also spreads out as deep as $5 \mathrm{~mm}$ before the current density drops to half of the high values. This fact, coupled with the relatively low bulk lifetime that we normally encounter for commercial PV-grade CZ-Si, implies that the surface effect is minimal. In addition, the influence is confined to the top surface, which is much less than that of a double-sided wafer of similar thickness. 
conduction

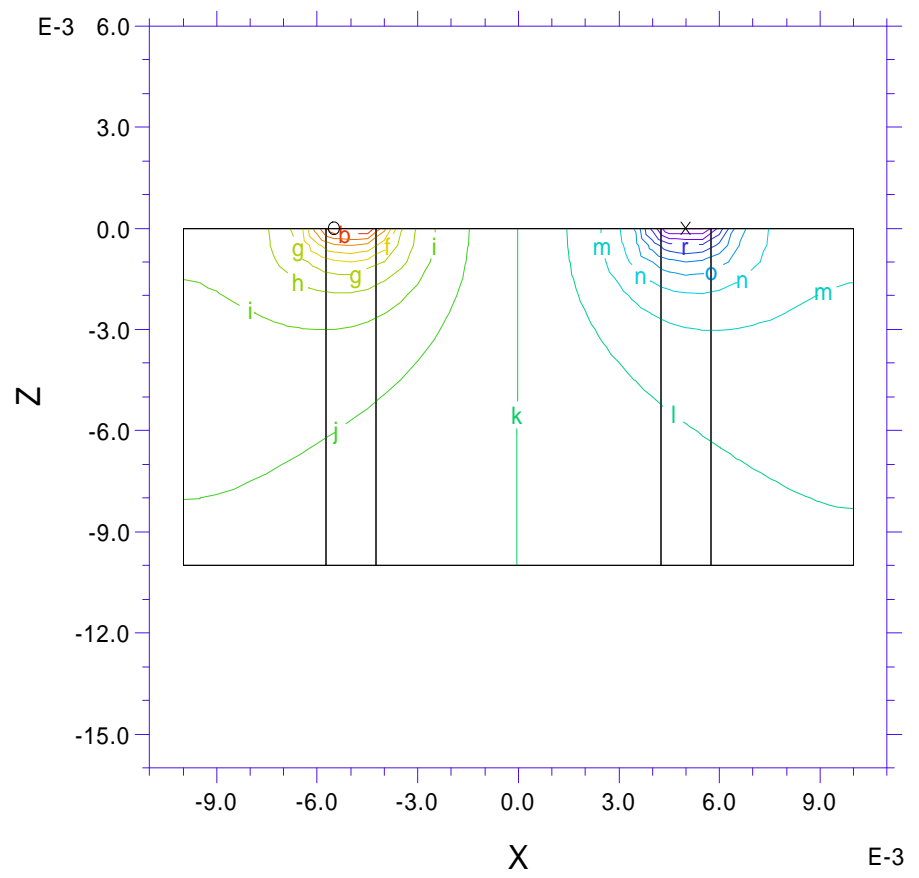

XZ potential surface $y=0$

$\max \quad 10.0$

u : $\quad 10.0$

$t: \quad 9.50$

s: $\quad 9.00$

$r: \quad 8.50$

q: $\quad 8.00$

$p: \quad 7.50$

o: $\quad 7.00$

n: $\quad 6.50$

$m: \quad 6.00$

1.5 .50

k: $\quad 5.00$

i. $\quad 4.50$

$\mathrm{h}: \quad 3.50$

g: $\quad 3.00$

$\begin{array}{ll}\mathrm{f}: & 2.50 \\ \mathrm{e} & 2.00\end{array}$

d: $\quad 1.50$

c: $\quad 1.00$

b: $\quad 0.50$

a : $\quad 0.00$

Fig. $3 b$ Electric-potential contours on the center vertical plane containing the probes.

conduction

18:

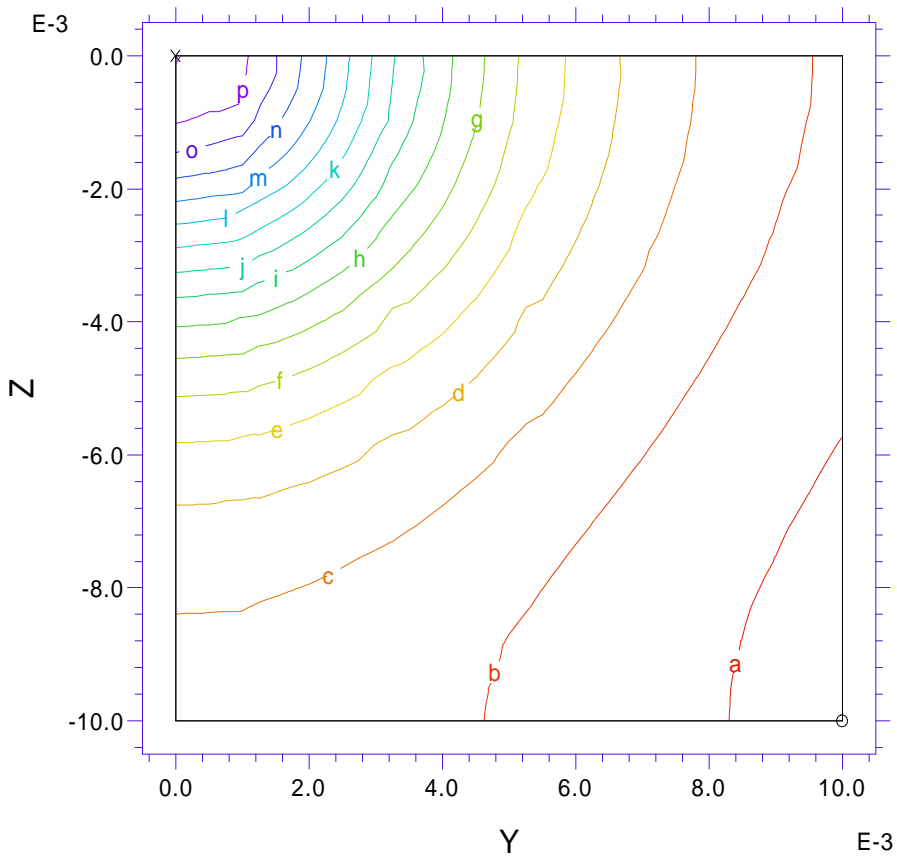

\begin{tabular}{ll}
\multicolumn{2}{c}{$\begin{array}{c}\text { current on } \mathrm{YZ} \text { at } \mathrm{cr} \\
\text { surface } \mathrm{X}=0\end{array}$} \\
\hline $\max$ & 3.81 \\
$\mathrm{q}:$ & 3.80 \\
$\mathrm{p}:$ & 3.60 \\
$\mathrm{o}:$ & 3.40 \\
$\mathrm{n}:$ & 3.20 \\
$\mathrm{~m}:$ & 3.00 \\
$\mathrm{l}:$ & 2.80 \\
$\mathrm{k}:$ & 2.60 \\
$\mathrm{j}:$ & 2.40 \\
$\mathrm{i}:$ & 2.20 \\
$\mathrm{~h}:$ & 2.00 \\
$\mathrm{~g}:$ & 1.80 \\
$\mathrm{f}:$ & 1.60 \\
$\mathrm{e}$ & 1.40 \\
$\mathrm{~d}:$ & 1.20 \\
$\mathrm{c}:$ & 1.00 \\
$\mathrm{~b}:$ & 0.80 \\
$\mathrm{a}:$ & 0.60 \\
$\mathrm{~min}$ & 0.51 \\
Scale $=\mathrm{E} 18$
\end{tabular}

Fig. 4 Current-density distribution at the center vertical plane between the probes.

Fig. 5 shows the calculated PCD signal with a surface recombination velocity of $10^{5}$ $\mathrm{cm} / \mathrm{s}$ compared with a signal with no surface effect. The surface effect only lowers the effective lifetime to $18.8 \mu$ s from the actual bulk lifetime of $20 \mu \mathrm{s}$. Therefore, as long as 
the measured lifetime is relatively low $(\sim 50 \mu \mathrm{s})$, the effective lifetime may be safely assumed to be the bulk lifetime, within measurement error.

:onauction

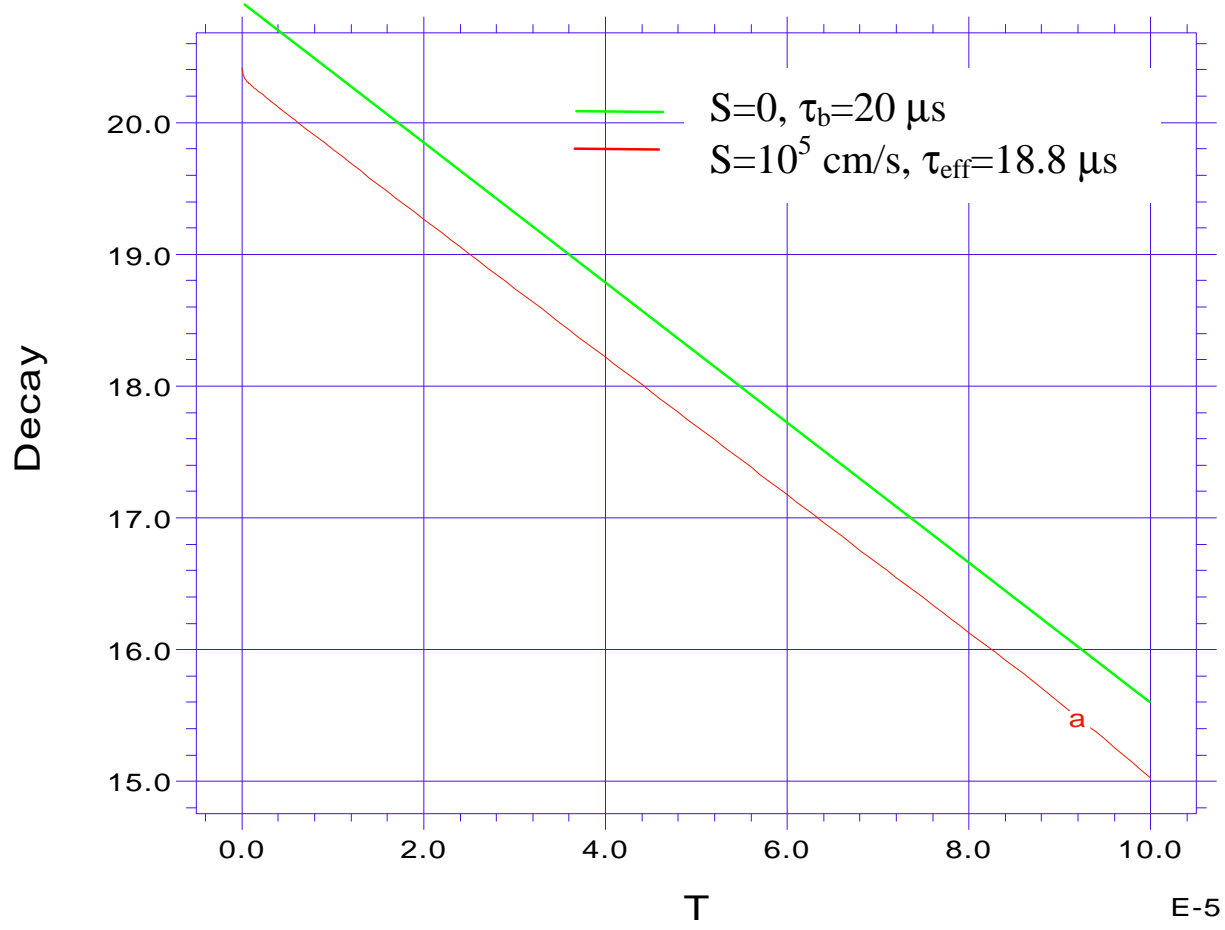

Fig. 5 Simulated PCD signal for surface effects (horizontal time scale in seconds).

In actual measurements, the initial segment of the signal should be ignored because of the high-order surface effect. The tail segment may also be ingnored because of complications arising from carrier drifting by the electric field to the contact area and possible trapping effects.

\section{MEASUREMENTS}

Initial results are reported here to demonstrate repeatability of the instrument and its effectiveness in distinguishing CZ-Si ingots grown from different feedstock sources.

\section{Repeatability}

A repeatability study in the form of balanced Analysis of Variances (ANOVA) [3] has shown that the instrument is capable of detecting the difference between a) the front and back of the ingots, and b) the locations on the same end of the ingot. In both cases, repeated measurement at the same location is not a significant source of variation, as Table 1 shows. The P-value is the probability that the source factor is not significant. 
Table 1. Repeatability Results of ANOVA

\begin{tabular}{lrrrrr} 
a) Analysis of & \multicolumn{2}{c}{ Variance for Lifetime. Ingot front and back. } \\
Source & DF & \multicolumn{1}{c}{ SS } & MS & F & P \\
\hline Ingot & 8 & 10303.80 & 1287.97 & 22.24 & $\mathbf{0 . 0 0 0}$ \\
Frt/Bck & 1 & 1579.34 & 1579.34 & 27.27 & $\mathbf{0 . 0 0 0}$ \\
ReptUp/Down & 2 & 25.80 & 12.90 & 0.22 & 0.801 \\
ReptOnly & 1 & 15.56 & 15.56 & 0.27 & 0.605 \\
Error & 95 & 5501.38 & 57.91 & & \\
Total & 107 & 17425.88 & & &
\end{tabular}

$\begin{array}{lrrrrr}\text { b) Analysis of Variance for Lifetime. Location. } & \text { for } \\ \text { Source } & \text { DF } & \text { SS } & \text { MS } & \text { F } & \text { P } \\ \text { Location } & 3 & 470.792 & 156.931 & 23.67 & \mathbf{0 . 0 0 0} \\ \text { ReptUp/Down } & 2 & 6.750 & 3.375 & 0.51 & 0.610 \\ \text { Reptonly } & 1 & 3.375 & 3.375 & 0.51 & 0.485 \\ \text { Error } & 17 & 112.708 & 6.630 & & \\ \text { total } & 23 & 593.625 & & & \end{array}$

\section{Separation by feedstock material}

Over four hundred ingots grown from remelt, virgin, and pot-scrap material blends have been measured by the lifetime tester. Remelt is scrap material from CZ ingots including tops and tails, whereas pot-scrap is residual materal left in the crucible from previous growth runs. Fig. 6 presents the lifetime values in different categories of source material. It is clearly seen that pot-scrap had lower lifetimes than remelt or virgin material.

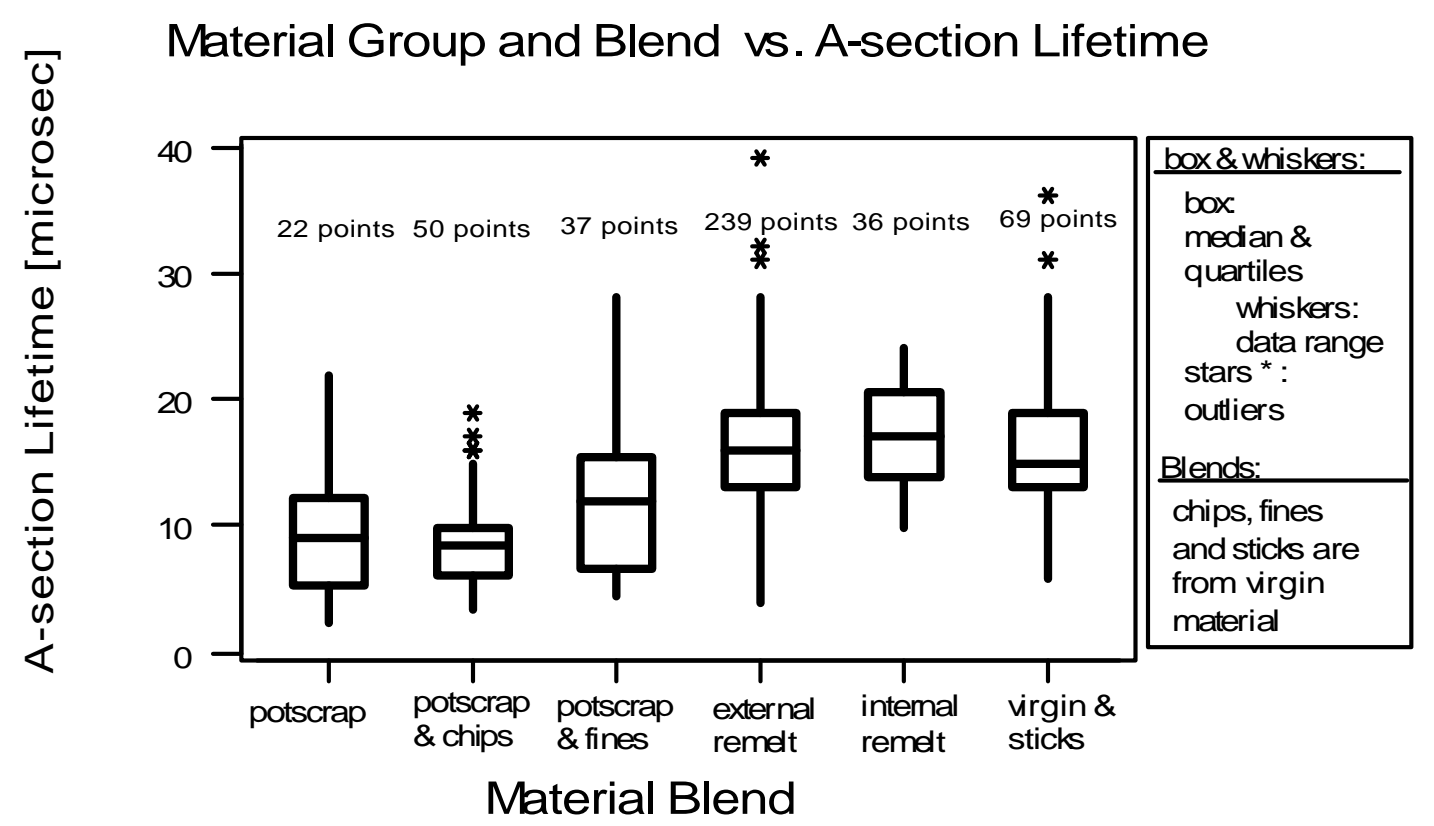

Fig. 6 Box plot for CZ-Si lifetimes vs. source material. Shown are median and quartile data, as well as highest and lowest values. 


\section{Separation by growth sequence}

Ingots occasionally lose their dislocation-free single-crystal structure during Czochralski growth. At that point, the ingot (A) is tailed and pulled from the melt and another ingot (B) is grown from the remaining silicon charge. Lifetimes of the tail ends of both A and B crystals are measured and are shown in Fig. 7. Note that A crystals always have dislocations at the tail ends, and yet, lifetimes of B crystals are usually lower. This indicates that the higher impurity content because of impurity segregation effect in $\mathrm{B}$ crystals has masked the possible effect of dislocations in A crystals.

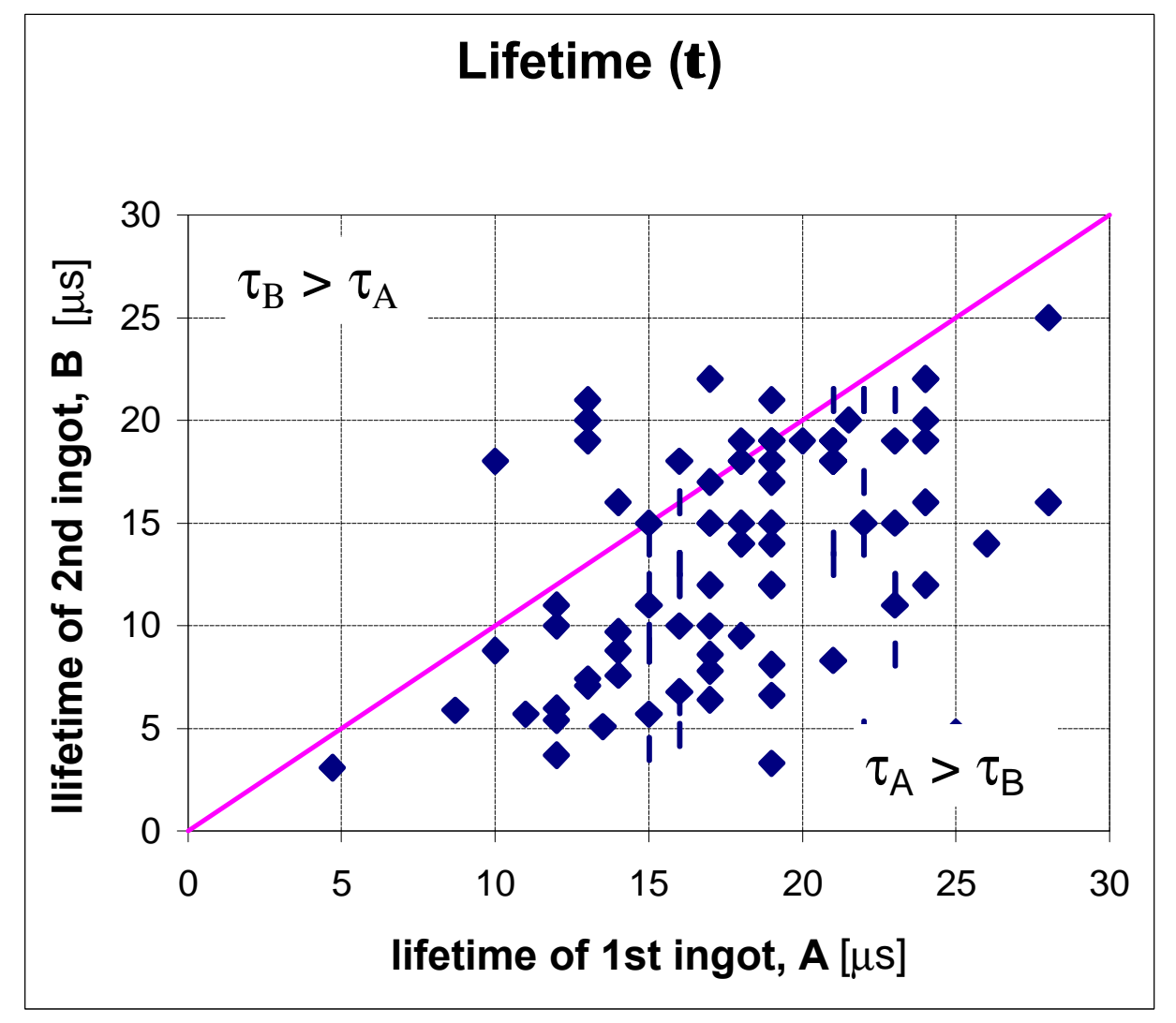

Fig. 7 Lifetime of tails of first (A) and second (B) run ingots.

\section{SUMMARY}

We have developed a lifetime instrument to characterize silicon ingots before they are subjected to expensive slicing and solar-cell processing. A 3-dimensional finite-element analysis indicates that the as-cut surface finish is adequate for measuring the bulk lifetime on the order of $50 \mu \mathrm{s}$ or less. Measurement repeatability and clear distinction among different grades of feedstock materials have been demonstrated.

Oxygen thermal-donor effects could be present in all the measurement results. To establish a relationship between ingot lifetime and final solar-cell performance (assuming 
no significant contamination down the processing line), thermal-donor annealing may be necessary before more reliable lifetime measurements can be made.

\section{ACKNOWLEDGEMENTS}

This project is supported by a funds-in CRADA between Siemens Solar Industries and the National Renewable Energy Laboratory and by the U.S. Department of Energy under Contract No. DE-AC36-83CH10093 to the National Renewable Energy Laboratory.

The authors thank D. Sheadel, A. Smith, J. Coleman, J. Palm, and T. Jester of Siemens Solar Industries for technical assistance and support.

\section{REFERENCES}

[1] ASTM F28-91, 1993 Annual Book of ASTM Standards, Vol. 10.05, 30.

[2] Wang, T.H. and Ciszek, T.F., "Effects of Sample Inhomogeneity and Geometry on Photoconductivity decay," Recombination Lifetime Measurements in Silicon, ASTM STP 1340, D.C. Gupta, F.R. Bacher, and W.M. Hughes, Eds., American Society for Testing and Materials, 1998, 88.

[3] Montgomery, D.C., Design and Analysis of Experiments, Wiley \& Sons, New York (1997). 